\title{
Operation Book Shift
}

By DONALD P. HAMMER

A NEW $\$ 800,000$ BOOKSTACK addition completed in November 1958 made it necessary to shift the entire one-and-ahalf million volume bookstack collection in the University of Illinois Library. Over a period of about four months the work of fifty students, each working from twelve to twenty hours a week, three half-time deck supervisors, and the fulltime bookstack librarian was needed to complete the project. Since this move was made while normal service was provided in the library, only a part of the deck supervisors' and the bookstack librarian's time could be devoted to the project. The cost of the move amounted to about twelve thousand dollars.

The new addition consisted of ten floors or decks with about twenty-two hundred shelves or about a fifty thousand-volume capacity per floor. The older sections of the bookstacks also consist of ten floors, but with about five thousand to fifty-five hundred shelves providing a book capacity of about a hundred and fifty thousand volumes per floor.

As in every library that reaches capacity or near capacity, many of the Dewey classes in the old building had to be broken at undesirable places in order to provide shelving space for rapidly expanding subject fields. At best, many patrons find a large library difficult to use, and such a condition of separation only intensifies the difficulties. It was hoped that this new addition would make possible a better shelving arrangement on some of the floors. In many cases this proved possible; in a few cases no improvement could be made because of a lack of shelf space for further expansion in spite of the new addition.

It had been previously decided that
Formerly on the University of Illinois Library staff, Mr. Hammer is now Head, Serials Unit, Purdue University Libraries.

the expansion available on each floor would be most useful in the future by distributing it more or less evenly throughout all the shelving. This decision made it necessary to account for all available expansion in both the old and new stack additions.

The first step in planning the occupation of the new stacks was to determine the exact amount of expansion in terms of whole shelves that would be available on each floor in both the old and new

The problem of accounting for all the odds and ends of empty shelving was solved in a very unconventional way. A piece of ordinary string was used as a measuring device.

A piece of string as long as a shelf was matched with as many empty portions of shelves as was necessary to reach the end of the string. This, then, indicated that one empty shelf was available. This procedure was continued throughout the bookstacks until the number of empty shelves on each floor was determined.

At the same time an actual count of all shelves, utilized or not, on each individual floor was made.

In accordance with the decision mentioned previously, it was necessary at this point to determine how much expansion per shelf was available. This was found by dividing the number of empty shelves in the old and new stacks as determined through the use of the string by the total number of shelves both used and empty, old and new.

As an example, if through the use of 
the string it was determined that there were 2,527 empty shelves on a certain floor, and by actual count it was determined that there was a total of 7,757 shelves, both utilized and empty, on the same floor, the 2,527 was then divided by the 7,757. This indicated that there was .325 expansion available per shelf. The decimal figure then had to be converted to inches to be useful. This was done by multiplying the decimal figure by the length in inches of a typical shelf; that is, $.325 \times 35=11.375$. This indicated that approximately eleven inches expansion could be left available on each shelf when the books were shifted on that particular floor.

After it was determined that sufficient future expansion was available on each floor for the preferred arrangement of the various Dewey classes, it was felt necessary to present the preferred plan in graphic form to all staff members concerned. Ten large floor plans were provided, one for each floor of the building, showing the exact position of all shelving. The proposed position of the major Dewey classes on the various floors with the possible expansion determined as explained above was illustrated by colored paper thumbtacked over the position of the shelving on each plan. The colored paper represented the area occupied by each class including expansion. This method made it simple, by moving the colored paper from place to place on the floor plans, to prove or disprove the feasibility of each staff member's hypothetically suggested shelving plan. In this manner a definite arrangement for all classes was agreed upon, and the actual book shifting could be done with confidence that the books intended for a certain area would fit into that area with sufficient space for expansion allowed.

The last of the mechanical problems involved was the need for a method that would maintain the planned expansion per shelf during the actual shifting. Ob- viously, this could not be done by eye alone since most of us are poor judges of space and distances. The use of rulers would certainly maintain constant expansion, but they would be clumsy to use.

This difficulty was overcome by cutting $2^{\prime \prime} \times 4^{\prime \prime}$ blocks of wood the length of the intended expansion to be left per shelf on each floor. The block was then placed on the right-hand side of a shelf as the shifting progressed and the books were shelved up to it. A book end was then put in place, and the block moved to the next shelf, ad infinitum.

This system, with its detailed planning, eliminated much of the guesswork from the shifting, and the amount of expansion planned per shelf was maintained.

On the whole, the system worked well. The expansion, however, had to be adjusted in some individual areas as the shifting progressed because of human error or because of the expansion needs of some subject fields over others.

In a few places the system did not meet expectations because of the lack of close supervision. As an example, the total number of shelves needed on each floor was known, but as the work progressed no record was kept of the number of shelves removed or added in order to adjust to the varying height of books.

It cannot be stressed enough that accuracy in using the string and in counting shelves was an absolute necessity. Carelessness in accounting for the odds and ends of empty shelves can easily throw off the whole approach. It is obvious that three inches or so ignored throughout several thousand shelves will total up to considerable shelf space.

Many people contributed ideas toward the development of this shifting system, and most of those people spent many hours in planning and supervision. It was only through this detailed planning that the system was successful. 